\title{
Impacts of Globalization and Conflicts on Business Performance and Possibilities of Its Solution
}

\author{
Peter Seemann ${ }^{1, *}$, Zuzana Stofkova ${ }^{2}$ \\ ${ }^{1}$ University of Zilina, Faculty of Operation and Economics of Transport and Communications, \\ Department of Economics, Univerzitna 1, 01026 Zilina, Slovakia
}

\begin{abstract}
.
Research background: The concept of globalization is interpreted by various authors in terms of its importance or content. Globalization refers to the process of gradually erasing the borders of nation-states, and economic globalization is the culmination of this process. The proof is the interconnectedness of economies around the world, where each economy reacts sensitively to fluctuations and changes in other economies.

Purpose of the article: The paper deals with the examination of conflicts in the work environment of selected companies and the subsequent formulation of suggestions and recommendations for improvement.

Methods: Nowadays, conflicts in industrial relations and failure to manage conflict situations are one of the biggest problems in companies. A quantitative questionnaire survey was used to find out the current situation in companies in terms of conflicts, specific causes of conflicts, the impact of conflicts on work performance, how employees resolve work conflicts, and their awareness of alternative conflict resolution, with whom employees most often come into conflict. The questionnaire was anonymous; therefore, the specific company names are not given. The numbers of 190 selected companies were contacted, and 93 of them were replied to the questionnaire, which forms a survey sample.

Findings \& Value added: The conclusion contains recommendations for individual respondent's businesses to successfully resolve and prevent conflicts in the workplace, and thus strive to build a peaceful working atmosphere without extra costs incurred ineffective conflict resolution. Furthermore, there is an evaluation of the economic aspect and demonstration of the benefits of acquiring and using the skills of alternative conflict resolution in the form of elimination of losses.
\end{abstract}

Keywords: conflicts in the workplace; conflicts solution; globalization; business performance.

JEL Classification: $J 24 ; O 15$; $I 25$

\footnotetext{
${ }^{*}$ Corresponding author: peter.seemann@,fpedas.uniza.sk
} 


\section{Introduction}

We encounter the concept of conflict in many areas of life. For this reason, the issue of conflict is given wide attention in various branches of the social sciences. We can specify it from various points of view, namely ethological, psychological, philosophical, historical, sociological, etc.

The conflict as an expression of the current claim of those interested (standing on opposite sides) for the same thing willing to fight for it. Two or more (to some extent) exclusive efforts, forces, tendencies meet here. At present, however, a comprehensive perception of conflict (conflict situations) is still coming to the fore, which requires an interdisciplinary approach to the study of this issue. [1]

Conflict is a mental state in which simultaneous or immediate succession is the meeting of two or more opposing equally strong motives, which require different or even contradictory decisions and actions. [2]

In work $[3,4]$, the author defines that conflict is a fact of our daily lives. They point out that any disagreement of goals, opinions and interests will result in conflict. This is especially true in a situation where people have the opportunity to satisfy their needs differently (when the importance of relationships is not a priority). Many people have different opinions, but this may not significantly affect their relationships. However, this idea does not exclude that incompatibility of activities, goals and interests causes conflicts.

One of the oldest materials in which the definition of conflict is first mentioned in the work [5]. His understanding of conflict is derived from the concept of the dynamics of the living space of the individual; with constantly acting psychological forces of varying intensity and valence (their effects are contradictory). The result is a specification of different types of conflict situations in which two opposing forces with positive valence act, two opposing forces with negative valence, or two forces, one of which has positive and the other negative valence.

Social life is not conceivable without conflicts and their settlement. In social practice, errors have occurred, occur and will occur. A person's life is closely connected with conflict situations. People get into conflicts with their principles, other times it is a conflict with valid ethical norms, with the law, etc. [6]

Conflicts are very important for development - it lies in resolving them. There is no point in avoiding conflicts or trying to remove them from the company. If we neglect conflict at a time when it can still be resolved rationally, it can result in emotional disputes that can only be resolved by promoting one's interests. The presence or absence of conflicts has a direct effect on the vitality of systems. They upset the balance of the system, thus dynamizing the systems. [7]

Conflict also arises when change occurs. This can be seen as a threat that needs to be questioned or defended, or when there is dissatisfaction - it can provoke an aggressive reaction. Conflict should not be condemned because it is a necessary result of progress and change and can (should) be used constructively. [8]

From the manager's point of view, it is possible to encounter two types of conflicts. In the first case, it is a conflict between you and another person. In the second type, you are not directly involved - a conflict between members of your team. According to the author, both types of conflicts negatively affect the team's results as well as the atmosphere. From the beginning of the conflict, the situation is usually not serious, but it can gradually worsen to an intolerable stage. [9-11]

In his work [12], the author describes conflict resolution as one of the central personnel activities that determine the professionalism of managers' staffing. It defines conflict as a natural and necessary part of human life in the company, as a consequence of different attitudes, intentions and especially efforts to promote individuals, respectively groups. The 
author mentions in the publication that the ability of managers to successfully resolve conflicts in the workplace is essential in ensuring the necessary quality of performance of managerial positions, but especially for creating desirable, good interpersonal relationships in working groups.

Based on his research [13], the author stated that people who can manage conflict can help the organizations in which they work to live up to the conditions for constructive conflict resolution. In this context, certain procedures must be in place to help identify incoming tensions promptly and to offer easy access to conflict resolution. The author emphasizes the need to create bodies in which there will be a meeting of contradictions and the balancing of different ideas of interest. Organizations may have different bodies, functions or institutions to resolve and resolve conflicts.

According to [14] is the best way to entrust the conflict to line managers and employees. Their main idea was to implement communication between employees and managers in the field of conflict management [15-18], to enable them to actively resolve conflicts, and to conclude joint agreements to improve their working relationships.

Effective management of conflicts in the workplace is associated with the development of collective relationships in the company. [19-22]

The main tools for reducing conflict potential in companies include creating a transparent environment, trust between individuals or groups, teams, etc. [22-25]

\section{The purpose of the case study and methods}

The main goal of the practical part of the case study is a detailed mapping of the situation of the addressed companies in terms of conflicts in the workplace to compile optimal proposals and recommendations for improvement.

The purpose of the article is also to find out whether the respondents know and apply alternative ways of resolving conflicts in a particular company.

Nowadays, it is almost a daily routine that we encounter unwanted situations, problems and conflicts. A person needs (not only) his peace and balance in the work environment, so that his performance is as high as possible and there is no loss due to negative circumstances (time, money, etc.).

The theory is acknowledged that humans are influenced not only by genetics but also by the environment and society around them. No human being is born with all the knowledge, skills, and also with a shaped nature. Therefore, if he wants to work on himself and prevent various conflicts, he must learn these qualities.

If a conflict arises in the company, the relevant employees should be able to resolve it with the least possible impact. In the theoretical basis, we discussed authoritative and alternative ways of resolving conflicts. As we have already mentioned, authoritarian ways resolve the conflict by using force and influence to gain as much for themselves as possible regardless of the other side. Alternative ways, on the other hand, are characterized by an effort to create a balance between the parties and space for free decision-making. The parties only check each other in the implementation of the agreement and if it turns out that they are not satisfied with it, they try to improve the solution themselves or with the help of a third party.

Due to insufficient knowledge in the field of conflict resolution, most companies still use authoritative methods (decision by an authority, arbitration, enforcement by force or court decision).

Thanks to this case study, we would like to achieve that people become more aware of alternative ways of resolving conflicts and can use them correctly in a specific situation. 
In this case study, we chose quantitative research to obtain objective and verifiable data within the researched issues. The questionnaire contained 25 questions, of which: 8 open questions, 2 semi-closed questions and 15 closed questions. For the scaling questions, we determined a scale from 1 to 10 , where 1 was the worst possible value and 10 was the best value.

The questionnaire was sent to 190 companies of various specializations. These included programming and information technology companies, advertising agencies, construction companies, various manufacturing companies, transport companies and many more. The questionnaire was anonymous, so we do not provide specific company names. Of the 190 selected, 93 companies that make up our sample answered us. This means that the return on the questionnaires in our case was $48.95 \%$.

\section{Results and discussion}

The majority of our sample is female $(65.60 \%$, i.e. 61 respondents). On the contrary, the minority consists of male respondents with a representation of $34.40 \%$ (32 employees).

One part is $55.90 \%$, which represents employees working in managerial positions (52 employees). The other $44.10 \%$ represent respondents working in other job positions (41 employees).

From the following graph, we can find out how the addressed respondents perceive the relations between employees in the relevant department.

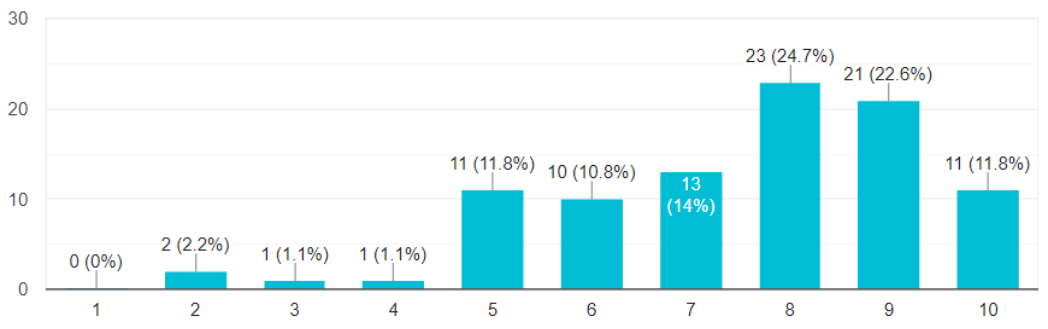

Fig. 1. Graphical representation of relationships between employees in different companies.

The largest representation of respondents, i.e. $24.7 \%$ (23 people) rated the relationships between employees in the same department at a value of 8 out of a total value of 10 . From this we can conclude that the relationships between the employees are not bad, they are good, although sometimes there can be a conflict between them, certain misunderstandings and the like. Eleven employees $(11.80 \%)$ rated the relationships between employees in the department at 10 out of a total number 10 (Fig. 1).

From the findings, we can conclude that the relationships with these employees are excellent and the work environment is non-conflicting. In these companies, we can assume that a certain "culture" in behaviour is established to prevent conflicts as much as possible, or the company provides specific training for employees, courses aimed at conflict prevention.

The worst evaluation from our questionnaire reached the value of 2 (marked by two respondents $-2.20 \%$ ). Employees of these companies and enterprises that have marked low values on the rating scale are advised to follow the recommendations that will be mentioned in section 4. 


\subsection{The most common ways to resolve conflicts}

For the case study, we selected the answers (How are conflicts in your department most often resolved? with the greatest telling value and ranked them from the most common to the answers that occur only rarely in the results (Table 1).

Table 1. The most common ways to resolve conflicts.

\begin{tabular}{|c|c|}
\hline Element & Style \\
\hline 1. Interview & $\begin{array}{l}\text { 9. With subordinates e.g. caution, with } \\
\text { suppliers compromising }\end{array}$ \\
\hline 2. By consulting the problem & $\begin{array}{l}\text { 10. Discussion and finding out the } \\
\text { cause of the conflict }\end{array}$ \\
\hline $\begin{array}{l}\text { 3. Discussion, explanation, concrete } \\
\text { argumentation }\end{array}$ & $\begin{array}{l}\text { 11. Usually they are not addressed, they } \\
\text { are just ignored or then there is a } \\
\text { discussion where they make } \\
\text { concessions but neither side is satisfied }\end{array}$ \\
\hline 4. A reprimand from the leader & 12. Clarification of job responsibilities \\
\hline 5. Communication in a meeting & $\begin{array}{l}\text { 13. If I am right, I will defend it, if I do } \\
\text { not give up }\end{array}$ \\
\hline 6. Sharpened communication & $\begin{array}{l}\text { 14. By consulting the problem, finding } \\
\text { the "golden mean" }\end{array}$ \\
\hline 7. They are not much addressed & 15. Customer-friendly \\
\hline $\begin{array}{l}\text { 8. Clearly by compromising or } \\
\text { reaching a consensus of the parties } \\
\text { involved }\end{array}$ & 16. By avoiding \\
\hline
\end{tabular}

The nature of the answers obtained varied. Some employees had a clear idea of the optimal solution to conflict situations (discussion, finding the cause, defining work compromises, etc.), others, on the contrary, sought a solution through sharpened communication, or did not solve the problem at all (avoidance, ignoring, etc.).

\subsection{The most common reasons for conflicts}

From the summary results, we state that the most common reason for conflicts in the workplace is the ambiguity of their responsibilities and competencies (27 people; $29.00 \%$ ). Therefore, each employee must clearly define job tasks and requirements that are expected of him and competencies, the range of which he cannot exceed. The second most common answer was the incompatibility of the needs of two people in a given situation (21 respondents; $22.60 \%$ ). People are different, and therefore the needs and ideas of two people are different. When two employees meet who have completely different perceptions of the same thing, it is highly likely that this situation could escalate into conflict. Another often referred answer (20 people; $21.50 \%$ ) was the use of different sources of data collection and interpretation. In the penultimate place was the answer to the different understanding of company values (16 employees; $17.20 \%$ ) and in the last place, there are conflicts due to dissatisfaction with another person ( 9 people; $9.70 \%$ ). 


\subsection{The most frequently achieved phase of the conflict}

The phases of conflict that you most often find yourself in the workplace are:

a) Symptoms of conflict - Emotional manifestations (tension, fear, anger, uncertainty), cognitive manifestations (thinking about the situation, what will happen next), physical manifestations (abdominal pain, fast heartbeat)

b) Opening the conflict - One side will say out loud what it thinks - it will open the dispute by saying demands. Negative emotions increase - it goes into an open dispute with another person.

c) Polarization - Both parties insist on their positions - persuasion, winning, blaming. Aggression, anger and other negative emotions are rising.

d) Isolation - Both sides are very aggressive, perceive helplessness in that the dispute would be resolved. They retreat into isolation.

e) Destruction - Physical harm, a humiliation in front of other people, threat, material destruction.

f) Fatigue - Fatigue and depression, common diseases, deterioration of work performance.

In this questionnaire, we wanted to find out what phase the respondents most often reach during a conflict (Fig. 2).

Most often they enter the second phase - the conflict opens up, the parties openly express their opinion, negative emotions rise, and an open dispute arises between the parties involved. Persons in number of 46 (49.5\%) reach this stage during the conflict respondents. Slightly smaller representation is given to employees who only get into the first phase of the conflict, symptoms of conflict - emotional, cognitive or physical manifestations appear (36 people; $38.70 \%$ ).

Respondents in number of $7-(7.50 \%)$ get into the third phase, into the so-called polarizations, where both sides insist hard on their positions, persuade, win, blame and rise negative emotions. Employees - 3 persons (3.20\%) marked the situation to solve the very offensive fourth phase when the feeling of helplessness prevails, and $1.10 \%$ of respondents (1 person) get into the last sixth phase of the conflict development - depression and various illnesses can manifest themselves here.

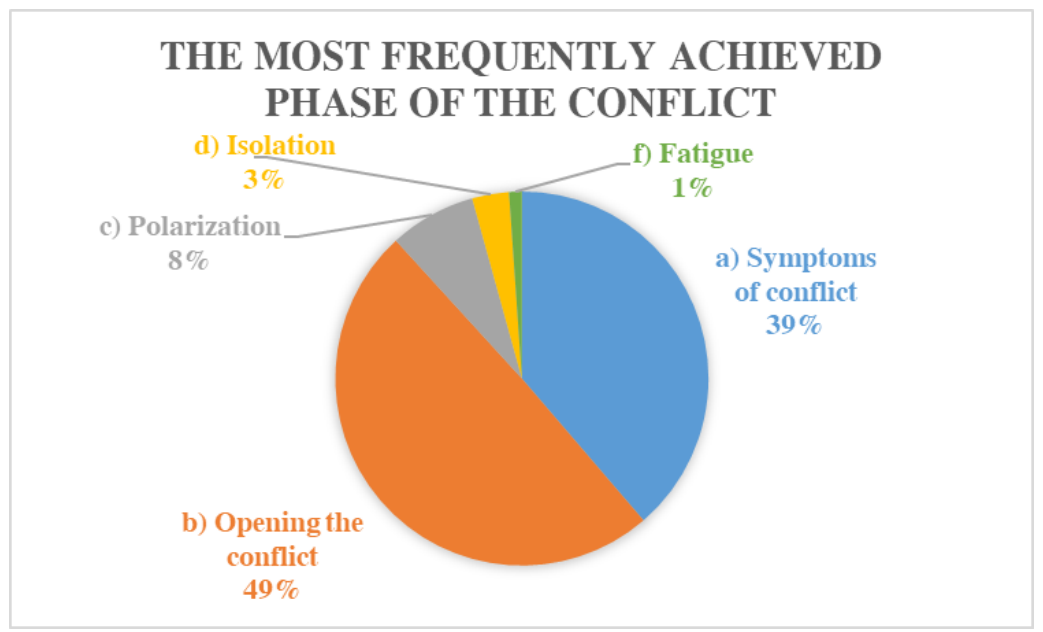

Fig. 2. The most frequently achieved phase of the conflict. 


\section{Conclusions}

We can say that most respondents work in a mildly conflicted environment and conflicts affect their work performance. Respondents most often came into conflict with colleagues at the same level and mainly due to the ambiguity of their responsibilities and competencies.

The most marked answer to which the respondents most often get into the conflict was the second phase - the opening of the conflict. Furthermore, we wanted to learn about the respondents' awareness of an alternative way of resolving conflicts in the work environment.

Therefore, we asked which alternative and authoritative ways of resolving conflicts in practice. It was clear from the results that the respondents are more inclined to alternative ways of resolving conflicts. The most common cause of conflict in specific departments was a lack or, on the other hand, an excess of information, which caused tensions between employees.

The largest percentage ended the conflict through joint communication, negotiations and efforts by both sides to make concessions. From the summary results, we saw the effort of respondents to increase their current level of ability to effectively resolve conflicts, for example, by improving communication, prudence, argumentation, empathy, etc. We could also notice the relatively more frequent occurrence of conflicts in the work environment and the associated loss of time and money caused by the ineffective resolution of the conflict.

Finally, we wanted to find out if the respondents would be interested in attending a course in the field of conflict resolution, which also focuses on alternative ways of resolving conflicts. An overwhelming majority of respondents expressed their agreement.

Other suggestions and recommendations:

- Engage more constructively in constructive dialogue,

- complete joint team buildings,

- not to rely on conflicts to resolve themselves, but on the contrary to start them tackle effectively,

- clearly define the responsibilities and competencies of individual employees,

- learn more about alternative ways of resolving conflicts and try abandoning authoritarian ways,

- provide employees with sufficient necessary information and not burden them redundant information,

- proper time management of employees,

- improve argumentation, be open and have a positive attitude towards other people

- not being subject to emotions and resolving conflicts with reason,

- regular training in the field of effective conflict resolution in the workplace, and thus reduce the negative impacts and consequences of conflicts.

We have formulated the mentioned suggestions and recommendations based on the answers recorded in the questionnaire survey. We dare to say that the procedure according to the mentioned suggestions and recommendations and also the completion of the proposed course can significantly improve workplace relations, prevent conflicts and effectively prevent them. Education in this area and the remedy itself is not in terms of time and difficulty simple, but the result of long-term efforts is ultimately a great benefit.

„This work was supported by the VEGA 1/0755/18 project.” 


\section{References}

1. Lempp, F., Blackwood, K., Gordon, M. (2020). Exploring the efficacy of mediation in cases of workplace bullying. International Journal of Conflict Management, 31(5).

2. Lewin, K. (2013). A dynamic theory of personality-selected papers. Read Books Ltd.

3. Dunford, B. B., Mumford, K. J., Boss, R. W., Boss, A. D., Boss, D. S. (2020). Integrated Conflict Management Systems Pay Off with Lower Levels of Formal Grievances and Lower Turnover Rates. ILR Review, 73(2), 528-551.

4. Currie, D., Gormley, T., Roche, B., Teague, P. (2017). The management of workplace conflict: Contrasting pathways in the HRM literature. International Journal of Management Reviews, 19(4), 492-509.

5. Kohlhoffer-Mizser, C. (2019). Conflict management-resolution based on trust? Ekonomicko-manazerske spektrum, 13(1), 72-82.

6. Belas, J., Smrcka, L., Gavurova, B., Dvorsky, J. (2018). The impact of social and economic factors in the credit risk management of SME. Technological and Economic Development of Economy, 24(3), 1215-1230.

7. Meyers, T. D., Vagner, L., Janoskova, K., Grecu, I., Grecu, G. (2019). Big Data-driven Algorithmic Decision-Making in Selecting and Managing Employees: Advanced Predictive Analytics, Workforce Metrics, and Digital Innovations for Enhancing Organizational Human Capital. Psychosociological Issues in Human Resource Management, 7(2), 49-54.

8. Wilkinson, W., Podhorska I., Siekelova A. (2019). Does the Growth of Artificial Intelligence and Automation Shape Talent Attraction and Retention?, Psychosociological Issues in Human Resource Management, 7(1): 30-35.

9. Clarke, H. M., Sulsky, L. M. (2019). The Impact of Gender Stereotypes on the Appraisal of Civic Virtue Performance. Journal of Research in Gender Studies, 9(2).

10. Martins, L. L. (2020). Strategic Diversity Leadership: The Role of Senior Leaders in Delivering the Diversity Dividend. Journal of Management, 46(7), 1191-1204.

11. Babalola, M. T., Stouten, J., Euwema, M. C., Ovadje, F. (2018). The relation between ethical leadership and workplace conflicts: The mediating role of employee resolution efficacy. Journal of Management, 44(5), 2037-2063.

12. Micieta, B., Durica, L., Binasova, V. (2018). New solution of abstract architecture for control and coordination decentralized systems. Tehnički vjesnik, 25(Supplement 1), 135-143.

13. Cilliers, J., Fleisch, B., Prinsloo, C., Taylor, S. (2020). How to improve teaching practice? An experimental comparison of centralized training and in-classroom coaching. Journal of Human Resources, 55(3), 926-962.

14. Allcock, D., Filatotchev, I. (2010). Executive incentive schemes in initial public offerings: The effects of multiple-agency conflicts and corporate governance. Journal of Management, 36(3), 663-686.

15. Lamberti, A. P., Richards, A. R. (2019). Communication and Conflict Studies: Disciplinary Connections, Research Directions. Springer Nature.

16. Kovacikova, M., Repkova Stofkova, K. (2016). Impact of globalization on access to process businesses management In: Kliestik, T. (Ed.), 16th International Scientific Conference on Globalization and its Socio-Economic Consequences (pp.1022-1030) Zilina: ?University of Zilina. 
17. Martins, L. L. (2020). Strategic Diversity Leadership: The Role of Senior Leaders in Delivering the Diversity Dividend. Journal of Management, 46(7), 1191-1204.

18. Micieta, B., Fusko, M., Binasova, V., Furmannova, B. (2020). Business model canvas in global enterprises. SHS Web of Conferences (Vol. 74, p. 02010). EDP Sciences.

19. Medvecka, I., Binasova, V., Kubinec, L. (2017). Planning and performance evaluation of the manufacturing organizations. Procedia engineering, 192, 46-51.

20. Durana, P., Valaskova, K., Vagner, L., Zadnanova, S., Podhorska, I., Siekelova, A. (2020). Disclosure of strategic managers' factotum: Behavioral incentives of innovative business. International Journal of Financial Studies, 8(1), 17.

21. Durana, P., Zauskova, A., Vagner, L., Zadnanova, S. (2020). Earnings drivers of Slovak manufacturers: Efficiency assessment of innovation management. Applied Sciences, 10(12), 4251.

22. Janoskova, K., Krizanova, A. (2017). Comparison of selected internationally recognized brand valuation methods. Oeconomia Copernicana, 8(1), 99.

23. Deming, D. J., Noray, K. (2020). Earnings Dynamics, Changing Job Skills, and STEM Careers. The Quarterly Journal of Economics, 135(4), 1965-2005.

24. Majerova, J., Sroka, W., Krizanova, A., Gajanova, L., Lazaroiu, G., Nadanyiova, M. (2020). Sustainable Brand Management of Alimentary Goods. Sustainability, 12(2), 556.

25. Gnap, J., Varjan, P., Durana, P., Kostrzewski, M. (2019). Research on relationship between freight transport and transport infrastructure in selected european countries. Transport Problems, 14(3), 63-75. 